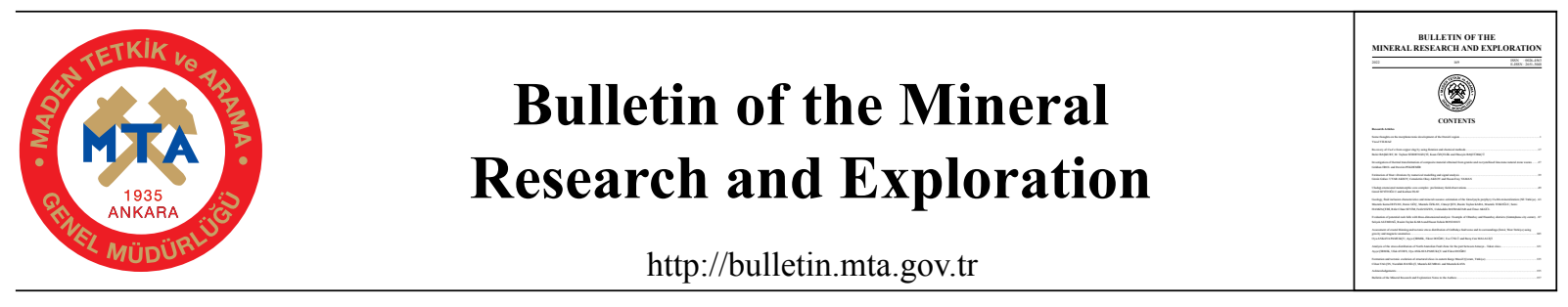

\title{
Estimation of blast vibrations by numerical modelling and signal analysis
}

\author{
Güzin Gülsev UYAR AKSOY ${ }^{a^{*}} \mathbb{D}$, Cemalettin Okay AKSOY ${ }^{b}$ and Hasan Eray YAMAN ${ }^{c}$ \\ ${ }^{a}$ Hacettepe University, Faculty of Engineering, Department of Mining Engineering, Ankara, Türkiye \\ ${ }^{\mathrm{b}}$ Dokuz Eylül University, Faculty of Engineering, Department of Mining Engineering, İzmir, Türkiye \\ ${ }^{\mathrm{c}}$ Dokuz Eylül University, Torball Vocational School, Department of Mining Engineering, İzmir, Türkiye
}

Research Article

Keywords:

Blasting, Vibration,

Seismic Wave, Numerical

Model, Mining.

Received Date: 17.03.2021

Accepted Date: 24.01 .2022

\begin{abstract}
Seismic waves carry all the geological and geotechnical characteristics of the units they pass along the route they travel on. Therefore, seismic waves can be called the signature of the route it passes through. If the blasting point is considered as source, blast-induced seismic waves measured at a certain distance from the source can be revealed and this form can be integrated into the dynamic numerical model, the effects that will occur at any point of the model can be predicted. In this study, seismic waves induced from single-hole blast and a group blast consisting of holes with the same characteristics as a pilot blast hole were obtained using particle velocity data obtained from seismographs at certain distances and integrated into the numerical model. The data processing technique used is to estimate the theoretical group blasting data from the pilot data according to the linear superposition principle and compare with the real group blasting data to determine the nonlinear behavior effect on the blast source from the difference. When the results were examined, it was observed that the numerical model results and field measurements coincided. The results of this study will make a significant contribution to the science of rock engineering.
\end{abstract}

\section{Introduction}

Especially in large scale mining activities, controlling seismic waves caused by blasts is of great importance. These waves not only negatively impact the stability of the benches in open pits but could damage the structures in underground mining as well. In both fields of mining and in tunneling, group blasts are performed in frequent intervals, nearly up to 3 times per day. Such blasts tire the rock mass over time and cause to reduce its strength. These could lead to landslides and caved zones. Research aimed to create full scale modelling of blast vibrations were limited due to the inclusions of many parameters. Most important of these is the number of discontinuity sets, their slope and slope direction. Sing and Narendrula
(2004) have calculated the peak particle velocity (PPV) of single discontinuity set in small scale blast experiments. According to their research, the lowest PPV was determined to be $113.3 \mathrm{~mm} / \mathrm{s}$ with $45^{\circ}$ as the discontinuity slope orientation and the highest PPV was obtained at $90^{\circ}$ which indicates the vibration transmission occurs parallel to the discontinuity set. Simangunsong and Wahyidi (2015), in addition to obtaining similar results in vibration determinations of discontinuities with different orientations and intervals, they reported a decrease in vibrations with increasing discontinuity. Zhou (2016) obtained similar results in the modeling study. Zou and Gong (2017) have reported an increase in PPV with increasing slope in bedded rocks, which correlate with the current

Citation Info: Aksoy Uyar, G. G., Aksoy, C. O.,Yaman, H. E. 2022. Estimation of blast vibrations by numerical modelling and signal analysis. Bulletin of the Mineral Research and Exploration 169, 39-48. https://doi.org/10.19111/bulletinofmre.1066943

*Corresponding author: Güzin GülsevUYAR AKSOY, gulsevaksoy@hacettepe.edu.tr 
results in literature. The greatest contribution to the estimation of blast vibrations were made by Blair (2020). Blair (2020) first examines the seismic wave propagation with the dynamic finite elements methods and subsequently developed the wave model with the Monte Carlo Waveform Superposition method which takes the effects of rock anisotrophy into consideration. Although in this study, no deformation module for the materials were not given; such module, the charge transport of the selected material and its ductility affect the wave propagation. To simulate the blast, load was applied to the middle of the model and with the results obtained from $4 \times 4 \mathrm{~m}$ single and double discontinuity, Monte Carlo Waveform Model was created. Upon examining the normalized model, even in the $4 \times 4 \mathrm{~m}$ model, an increased distance from the middle of the model results in a decrease in similarity of the wave propagation patterns between the AFEM and the polar approach results. Although blasts being performed in considerably larger areas poses a challenge in application of Blair's aforementioned study, it is a very valuable contribution to the literature.

Biggest disadvantages of such modelling studies is the challenges faced in representing the field of the full scale blast as the number, slope, direction and orientation of discontinuities are never constant. Furthermore, stress in nature is three dimensional. Blast induced seismic waves propagate in different directions in different rates. In other words, seismic waves caused by a blast, due to varying attributions different parts of a rock mass has, propagate and are absorbed in different directions and rates. Additional, it is known that rock environment shows non-linear characteristics in regions close to blasting (Uyar and Aksoy, 2019). Meaning, there are behavioral differences in measurements of the waveforms, taken from a closer and further point of distance to the blast. In closer distances, occurrences of plastic deformation (fracturing) are observed whereas in further distances these events do not occur and only elastic deformation are observed.

The main aim of this study is to estimate seismic vibrations induced by blasts from a selected distance using three dimensional dynamic finite elements method in order to overcome challenges in full field modelling. Critically, it is important to have a correct estimation of the energy in the source in order to give correct input parameters to the numerical model. To achieve this, a nonlinear response signal is used, which is obtained by proportioning the seismic waves in the spectral media resulting from the pilot blast and the group blasting of holes, each of which is prepared as a pilot blast hole. Details of the method are given in the following chapter. Field studies to develop the method were performed in a gold mine. The model is solved by integrating the waveform at the zero point (source) obtained using the pilot and group blasts data into the 3D dynamic numerical model. Then, using the pilot blast signal, group blast was designed using the method we recommended that minimalizes the vibrations with the most suitable delay (Uyar and Ecevitoğlu, 2008). The group blast done, the velocities of the particles that were caused by the blast induced seismic waves were calculated at desired distances and compared to the findings of the numerical model. The results are highly coherent. Therefore, by the results of this study, using the numerical modelling it is possible to estimate the propagation of group blast induced seismic waves and their vibrations related to the distance.

\section{Calculation of Blast Induced Seismic Energy in the Source and Target Point}

There are two ways of input for the blast induced seismic energy to the 3D dynamic model;

i) as peak particle velocity or acceleration rate,

ii) as seismic waveform.

With the results obtained from the experiments of underground and ground blasts conducted for our TÜBİTAK project finalized in 2017 (Aksoy and Uyar, 2014), seismic energy of the source was produced for both cases. Studies conducted in those days aiming to realistically input the dynamic effects of the blasts performed in stability analyses of the mining slopes created using numerical models, through time, has transformed into estimating, if the energy in the blast source is known, the effects of desired distances to the blast using the 3D dynamic numerical modelling method. This means the demolishing the paradigm of using empirical equation related to the PPV - SD (peak particle velocity, scaled distance) which does not go any further than reinforcing the convention 
of its usage since 1960's. Below are both methods of estimating seismic energy at the blast source and an exemplary comparative study performed with one.

\subsection{Estimating Explosive Acceleration (or Particle} Velocity) at the Source and Target Points

Steps of the process to be followed are given below (Aksoy and Uyar, 2014):

1. Sample explosive is placed upon the blast point.

2. A seismograph is placed on a relatively safe and close distance. The top of the seismograph could be covered (without the cover touching the device) to avoid damage inflicted by the flying debris.

3. Blast is performed and the acceleration of the closest particle to the blast zone $A_{0}$ is calculated.

4. Using Equation 1, the scale coefficient $k$ is calculated.

5. Particle-acceleration at the target point $B_{0}$ is calculated.

6. Using Equation 2, absorption coefficient $\alpha$ is calculated.

7. Using Equation 3, particle-acceleration of the actual explosive at the blast point, $A$, is calculated.

8. Using Equation 4, particle-acceleration of the actual explosive at the target point, $B$, is calculated.

Using Equation 5, limit mass of the actual explosive is calculated.

$$
\begin{aligned}
& k=\frac{A_{0}^{2}}{m_{0}} \\
& \alpha=\frac{\ln \frac{A_{0}}{B_{0}}}{x_{0}}
\end{aligned}
$$

$$
\mathrm{A}=\sqrt{k m}
$$

$$
\mathrm{B}=\mathrm{A} e^{-\alpha}
$$

$m_{\text {limit }}=\frac{\left(B_{\text {limit }} e^{\alpha x}\right)^{2}}{k}$

$a_{e}=\frac{\sum_{i=1}^{n} a_{i} \Delta x_{i}}{\sum_{i=1}^{n} \Delta x_{i}}$
In these equations the components are as follows; $\mathrm{k}$ : calculated scale coefficient $\left(\mathrm{g}^{2} \mathrm{~kg}^{-1}\right), A_{0}$ : particle acceleration measured at the blast point of the sample explosive $(\mathrm{g}), m_{0}$ : mass of sample explosive $(\mathrm{kg}), \alpha$ : calculated absorption coefficient $\left(\mathrm{m}^{-1}\right), B_{0}$ : particle acceleration $(\mathrm{g})$ of the sample explosive measured at the target point, $x_{0}$ : the distance between explosion point and sample explosion target point (m), $A$ : particle acceleration $(\mathrm{g})$, calculated at the blast point of the actual explosive, $m$ : mass of actual explosive $(\mathrm{kg})$ (probably $\left.\mathrm{m}>\mathrm{m}_{0}\right), B$ : calculated particle-acceleration $(\mathrm{g})$ of the original explosive at the target point, $x$ : distance (m) between the blast point and the actual blast target point (probably $x>x_{0}$ ), $\Delta x$ : distance between near and far stations (m), $\alpha_{e}$ : effective absorption coefficient $\left(\mathrm{m}^{-1}\right)$, $n$, $i$ : number of measurements, $m_{\text {limit }}:$ the limit mass of the actual explosive $(\mathrm{kg}), B_{\text {limit }}$ : selected limit particle acceleration of the actual explosive at the target point (g).

Calculating $\alpha_{e}$ in the Equation 6 at once, for far distances the energy produced by blasting induced for seismic source cannot reach is not possible. It is necessary to stay within the $\Delta x$ spacing to record seismic signals. Due to the field conditions, $\Delta x$ 's could have spacing in between, overlap or go beyond the line. In that case, partial measurements are made, using the Equation 2, mean values of $\alpha$ are calculated. $\alpha_{e}$ effective absorption coefficient is calculated from the distance-weighted average of the $\alpha$ mean absorption coefficients with the help of Equation 3. In other words, $\alpha_{e}$ is the distance weighted average of absorption coefficiencies of $\Delta x$ spacing. In this study, the reason for calculating $\alpha$ (absorption coefficient) is the separate calculations of $\Delta x$ efficiencies. $\alpha_{e}$ is used as the ultimate value. These equations were tried on a study, application parameters of which are given in Table 1 . The study was conducted using the blast acceleration parameters obtained from a blast performed in İmbat underground coal mine in 2016. A total of $28.8 \mathrm{~kg}$ of explosives were used for the aforementioned blast. 
Table 1-Acceleration - distance table of blasting at İmbat underground coal mine.

\begin{tabular}{|c|c|c|}
\hline Geophone & Distance $(\mathrm{m})$ & Acceleration $(\mathrm{g})$ \\
\hline 13638 & 31.5 & 1.564 \\
\hline 12270 & 42.0 & 0.835 \\
\hline 12269 & 52.5 & 0.742 \\
\hline 14465 & 63.0 & 0.517 \\
\hline
\end{tabular}

$k=\frac{A_{0}^{2}}{m_{0}}=\frac{1.564^{2}}{28.8}=0.0849 \mathrm{~g}^{2} \mathrm{~kg}^{-1} ; \alpha=\frac{\ln \frac{A_{0}}{B_{0}}}{x_{0}}=\frac{\ln \frac{1.564}{0.875}}{10.5}=0.0553 \mathrm{~m}^{-1} ;$

$\alpha=\frac{\ln \frac{A_{0}}{B_{0}}}{x_{0}}=\frac{\ln \frac{1.554}{0.742}}{21}=0.0355 \mathrm{~m}^{-1} ; \alpha=\frac{\ln \frac{A_{0}}{B_{0}}}{x_{0}}=\frac{\ln \frac{1.564}{0.517}}{31.5}=0.0351 \mathrm{~m}^{-1} ;$

$a_{e}=\frac{0.0553+0.0355+0.0351}{3}=0.042 \mathrm{~m}^{-1}$;

$\mathrm{A}=\sqrt{k m}=\sqrt{0.0849 \times 100}=2.9138 g$;

$\mathrm{B}=\mathrm{A} e^{-\alpha x}=2.9138 e^{-0.042 \times 63}=0.02067 g$;

$m_{\text {limit }}=\frac{\left(B_{\text {limit }} e^{\alpha x}\right)^{2}}{k}=\frac{\left(0.1 e^{0.042 \times 63}\right)^{2}}{0.0849}=23.4 \mathrm{~kg}$

Using the blast data with the formula, the results obtained can be interpreted as the following: When the explosive amount $\mathrm{m}=100 \mathrm{~kg}$, an acceleration of $2.9138 \mathrm{~g}$ is caused at the blast point. From a $\mathrm{x}=63 \mathrm{~m}$ distance to the blast point, an acceleration of $\mathrm{B}=0.2067 \mathrm{~g}$ is caused. To obtain a $0.1 \mathrm{~g}$ acceleration, the amount of explosives must be reduced to $23.4 \mathrm{~kg}$.

\subsection{Estimation of Seismic Waves at the Source and} Target Points

To estimate the seismic waves at the source parametrically, it is necessary to gather seismic wave data using two seismographs, one placed at the closest distance (e.g. $10 \mathrm{~m}$ ) with the possibility of saturation in the pilot blast field, the other placed in a distance to the first seismograph on the same line of path. Then, group blast routinely performed in the field for the excavation works, and measurements are repeated. Using the energy of the pilot blast, the energy that would be created by the amount of desired explosives is theoretically calculated, meaning the total seismic energy arising from the group blast is theoretically calculated. Energy caused by the actual group blast is also calculated and its ratio to the theoretical values are taken. This demonstrates how much of the energy is lesser than it is supposed to be, which represents the part measured with the seismograph, the elastic part. The remaining energy is the plastic energy used in rock fracturing, the energy that is used as the source data in the numerical model. Therefore, for that field, the plastic energy for the desired amount of explosives and the elastic energy in the target point desired is calculated. In a change of environment, pilot blast must be repeated and the data must be reconstructed.

\section{Field Study Using the Recommended Method}

The field study is conducted on a gold mine. Prominent rocks in the field are volcanic, metamorphic and intrusive rocks. Volcanic rocks can be found in the blast zone. These data is gathered from the field.

\subsection{Calculation of Seismic Energy in the Source}

Seismic waves caused by the group blast performed on 13.01.2021 at locations titled SV-GRUP and SV-PILOT in the Figure 1 were recorded by 4 seismographs. Seismograph locations were shown in Figure 1 with each device named after its serial number (13638, 12269, 12270 and 14465).

Design information related to the group and pilot blasts are given in Table 2, blast induced vibration, frequencies and duration data are given in Table 3.

To input a time-sequence of the blast for the numerical model, time sequences were created using the data obtained from group and pilot explosions and saves as an asci.txt file. In the practical part of the study, two ascii.txt files were used, both of which were seismic records obtained from the gold mine, from a $10 \mathrm{~m}$ distance to the source. First file, is the seismic signal in which the explosive amount is $20 \mathrm{~kg}$ (pilot hole). Second file is the data sheet for the group blast consisting of 84 holes. Each hole in the group blast is filled with $20 \mathrm{~kg}$ of explosive material, same as the pilot hole.

The pilot blast is situated nearby the group blast. First, the seismic signal resulting from the pilot blast was gathered 84 times and the total signal created by the blast of the $84 \times 20 \mathrm{~kg}$ explosive with a delay between the holes was produced, and then compared with the actual group blast signal. Using the difference between, theoretical signal that the desired amount of explosives would generate from the pilot blast signal. The Energy.EXE program that occurs when the program is run asks 3 questions: 


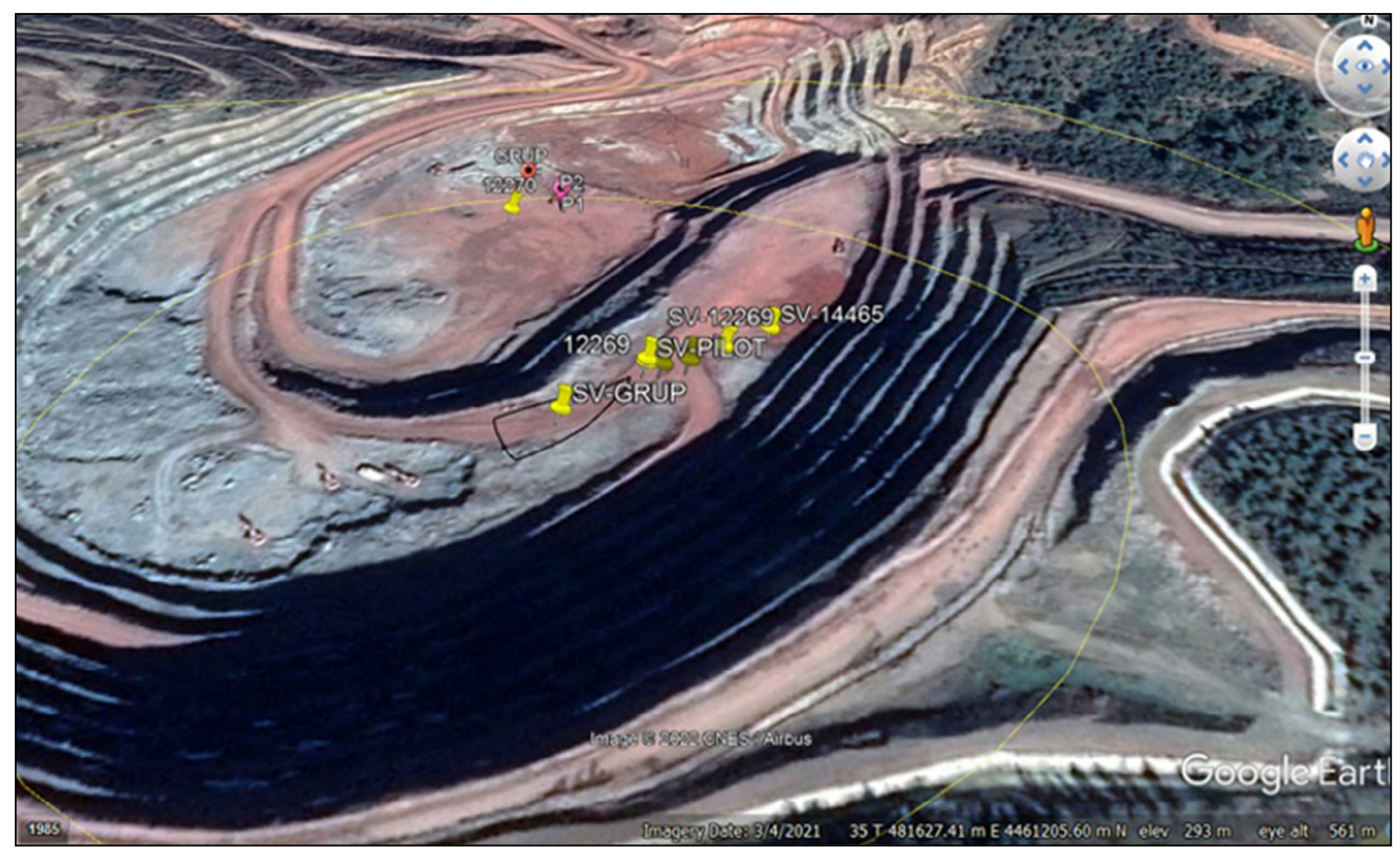

Figure 1- 13.01.2021 Group and pilot blasting and seismograph locations.

Table 2- Blasting pattern of group and pilot blasts.

\begin{tabular}{|c|c|c|c|c|c|c|c|c|}
\hline $\begin{array}{c}\text { Blasting } \\
\text { Area }\end{array}$ & $\begin{array}{c}\text { Blasting } \\
\text { Type }\end{array}$ & $\begin{array}{c}\text { Rock } \\
\text { Mass }\end{array}$ & $\begin{array}{c}\text { Drill Hole } \\
\text { Diameter }\end{array}$ & $\begin{array}{c}\text { Drill Hole } \\
\text { Geometry }\end{array}$ & $\begin{array}{c}\text { Number of } \\
\text { Drill Hole }\end{array}$ & $\begin{array}{c}\text { Drill Hole } \\
\text { Length }\end{array}$ & Q & Delay \\
\hline \multirow{2}{*}{$\mathrm{sV}$} & Pilot & \multirow{2}{*}{ Volcanic } & $102 \mathrm{~mm}$ & $3 \mathrm{mx} 3.5 \mathrm{~m}$ & 1 & $5-6 \mathrm{~m}$ & $\begin{array}{c}20 \mathrm{~kg} \text { Anfo, } 0.5 \mathrm{~kg} \text { primer } \\
\text { dynamite }\end{array}$ & $\begin{array}{c}42 \mathrm{~ms} \text { delay between holes; } \\
67 \mathrm{~ms} \text { delay between rows }\end{array}$ \\
\cline { 2 - 9 } & Group & & $102 \mathrm{~mm}$ & $3 \mathrm{mx} 3.5 \mathrm{~m}$ & 84 & $5-6 \mathrm{~m}$ & $\begin{array}{c}20 \mathrm{~kg} \text { Anfo, } 0.5 \mathrm{~kg} \text { primer } \\
\text { dynamite }\end{array}$ & $\begin{array}{c}42 \mathrm{~ms} \text { delay between holes; } \\
67 \mathrm{~ms} \text { delay between rows }\end{array}$ \\
\cline { 6 - 9 }
\end{tabular}

Q: Explosive amount per delay

Table 3- Blasting induced measured vibration, frequency and duration data.

\begin{tabular}{|c|c|c|c|c|c|c|c|}
\hline Seismograph & $\begin{array}{c}\text { Distance } \\
\text { m }\end{array}$ & $\begin{array}{c}\text { Transversal } \\
\mathrm{mm} / \mathrm{s}\end{array}$ & $\begin{array}{c}\text { Vertical } \\
\mathrm{mm} / \mathrm{s}\end{array}$ & $\begin{array}{c}\text { Longitudinal } \\
\mathrm{mm} / \mathrm{s}\end{array}$ & $\begin{array}{c}\text { Vector Sum } \\
\mathrm{mm} / \mathrm{s}\end{array}$ & $\begin{array}{c}\text { Frequency } \\
\mathrm{Hz}\end{array}$ & $\begin{array}{c}\text { Duration } \\
\text { second }\end{array}$ \\
\hline \multirow{2}{*}{12270} & Pilot:5 & 183.1 & 180.1 & 217.6 & 260.8 & 2 & 0.2 \\
\hline & Group:10 & 90.68 & 63.50 & 49.40 & 96.02 & 22 & 0.5 \\
\hline \multirow[t]{2}{*}{13638} & Pilot:10 & 24.26 & 38.86 & 42.80 & 48.65 & 21 & 0.2 \\
\hline & Group:15 & 40.51 & 65.02 & 31.37 & 66.67 & 22 & 1 \\
\hline \multirow[t]{2}{*}{12269} & Pilot:20 & 23.75 & 36.83 & 41.02 & 54.27 & 35 & 0.2 \\
\hline & Group:30 & 19.30 & 36.96 & 31.62 & 44.84 & 24 & 1.2 \\
\hline \multirow[t]{2}{*}{14465} & Pilot:40 & 11.81 & 38.86 & 12.70 & 39.08 & 30 & 0.5 \\
\hline & Group:45 & 18.54 & 35.18 & 19.30 & 39.21 & 24 & 1.2 \\
\hline \multirow{2}{*}{ Micro } & Pilot:261 & 0.875 & 1.324 & 1.915 & 2.317 & 7.5 & 1 \\
\hline & Group:303 & 2.514 & 3.003 & 3.153 & 3.927 & 12 & 1.5 \\
\hline
\end{tabular}


1) Big-charge filename (no TXT):

For example: $12270-\mathrm{G}$

2) Small-charge filename (no TXT) :

For example: 12270-P

3) Multiplication factor :

For example: 84

Figure 2, shows this screen.

Energy.EXE creates 3 new files:

1)_maxi file

For example: source_maxi.dat

The PPV in the 12270-P.TXT file synchronized with the PPV $(96.02 \mathrm{~mm} / \mathrm{s})$ in the $12270-$ G.dat file.

2)_multi file

For example: source_maxi.dat

The PPV in the 12270-P.TXT file multiplied by the Multiplication Factor (84).

3) Rapor.TXT file

Big-charge energy: Transversal Vertical Longitudinal Small-charge energy: Transversal Vertical Longitudinal
Maximum energy: Transversal Vertical Longitudinal Multiplier energy: Transversal Vertical Longitudinal

From the above energy levels, what percentage of the energy would be spent on elastic wave propagation and what percentage would be spent on plastic deformation can be calculated (Uyar et al., 2014).

Wave form represented by red in Figure 3 is the theoretical transversal component particle velocity data gather from the pilot blast being summed for 84 times (with delay between holes). Blue is the theoretical transversal component particle velocity data normalized to the highest PPV observed in the group blast. The amplitude expansion being only 4,7 times $(96 \mathrm{~mm} / \mathrm{s} \times 84) /(1680 \mathrm{~mm} / \mathrm{s})$, rather than 84 , indicates the prominence of a non-linear behavior in the environment. A majority of the energy is spent for the plastic deformation. Source energy calculated this way is integrable into the $3 \mathrm{D}$ dynamic numerical model as asci.txt file.

\subsection{Three Dimensional (3D) Numerical Modelling Phase of the Study}

Pilot blast, group blast and seismographic data, the locations of which were given in Figure 1 are defined in Plaxis 3D as seen in Figure 4.

The study area consists of volcanic rocks. Rock parameters used in the 3D model are given in Table 4.

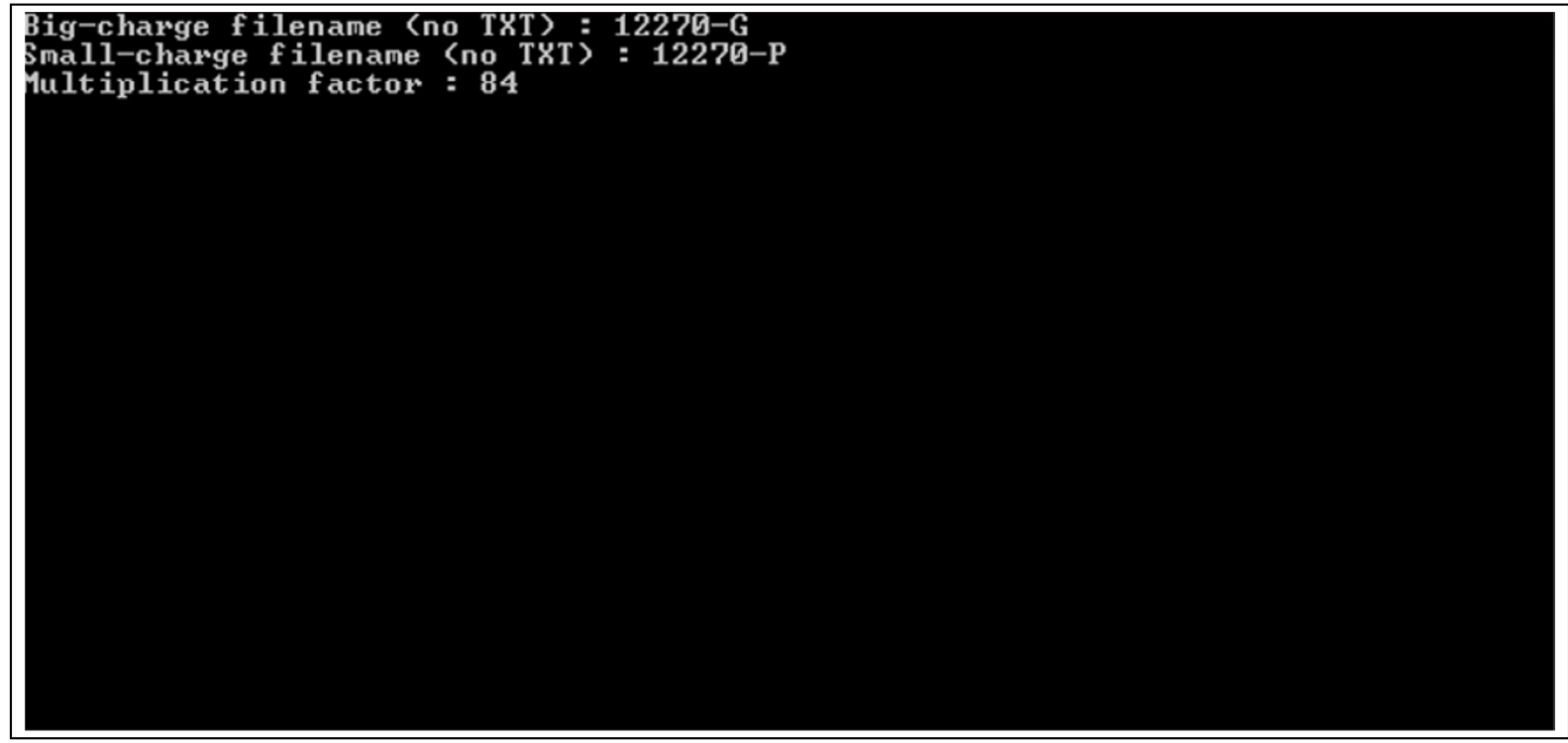

Figure 2- Screenshot of running the Energy.EXE program. 


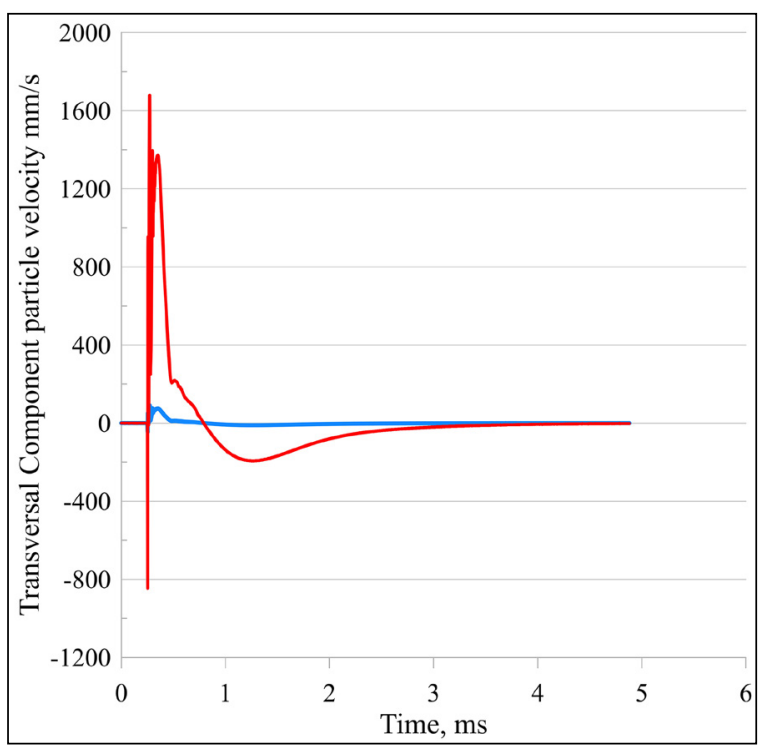

Figure 3- Seismic energy at zero point: The (red) seismic waveform obtained by linear summation of the pilot signal and calculated according to the non-linear behavior (blue).

The accepted one is the blue one.

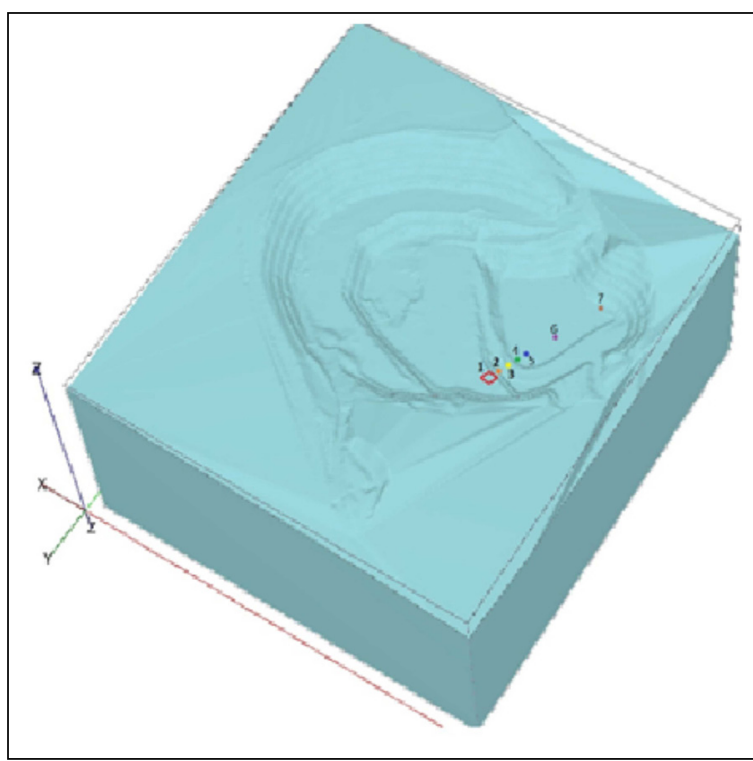

Figure 4- Group and pilot blast and seismograph locations defined in the model. No:1 blast location; No: 2, 3, 4, 5, 6, 7 seismograph locations.

Table 4- Rock parameters used in numerical modeling.

\begin{tabular}{|c|c|c|c|c|c|}
\hline Rock Type & $\begin{array}{c}\text { Deformation } \\
\text { Modulus (MPa) }\end{array}$ & $\begin{array}{c}\text { Cohesion } \\
(\mathrm{kPa})\end{array}$ & $\begin{array}{c}\text { Internal Friction Angle } \\
\left({ }^{\circ}\right)\end{array}$ & $\begin{array}{c}\text { Unit Volume Weight } \\
\left(\mathrm{kN} / \mathrm{m}^{3}\right)\end{array}$ & $\begin{array}{c}\text { Poisson } \\
\text { Ratio }\end{array}$ \\
\hline Volcanic Rock & 553.2 & 667 & 24.34 & 24 & 0.25 \\
\hline
\end{tabular}

Distances of seismographs to the blast area are given below;

-Seismograph 2. 10 meters; Seismograph 3. 15 meters

-Seismograph 4. 30 meters; Seismograph 5. 45 meters

-Seismograph 6. 100 meters; Seismograph 7. 200 meters

The seismic wave velocities obtained by integrating the blast source data at the blast point into the numerical model are compatible with the actual blast induced seismic waves in all components (lateral, vertical and longitudinal). This compatibility is shown in Figures 5, 6 and 7.

This was verified by testing with another source data, nevertheless, only the comparison from the gold mine was examined in this study as to save space. Upon the observation of the mentioned correlation, predictions of the numerical model at distances of 20 ,
30 and $40 \mathrm{~m}$ were given below, compared to the actual blast data (Figure 8, Figure 9 and Figure 10).

In the numerical model, total deformation amount that varies according to the distance is also shown. As seen in Figure 11, blast induced deformations are zero. The change in seismic quality factors of the blast induced seismic waves, calculated using the 10 and $40 \mathrm{~m}$ distanced seismograph data must also be noted (calculation of seismic quality factor using blast waves was published by us in 2020) (Aksoy and Aksoy, 2020). A variation of 0.43-0.85 in seismic quality factor is observed for the first 40 meters which subsequently increases to 3.12 past 40 meters. The capability to determine the zero deformation point by the numerical model, this point being coherent to the seismic quality factor calculations, the fact that the non-linear behavior displayed by the blast is within 40 $\mathrm{m}$ leads us to understand that the seismic waves past this distance display linear behavior. 


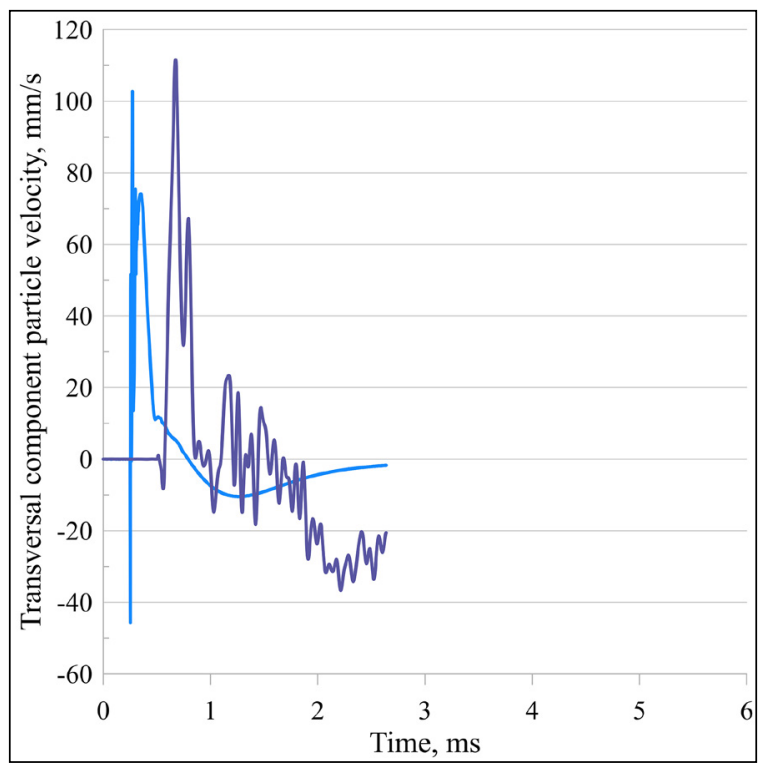

Figure 5- Comparison of the actual blast transversal component source signal and the predicted signal by numerical modeling (light blue real data vs dark blue numerical modeling data).

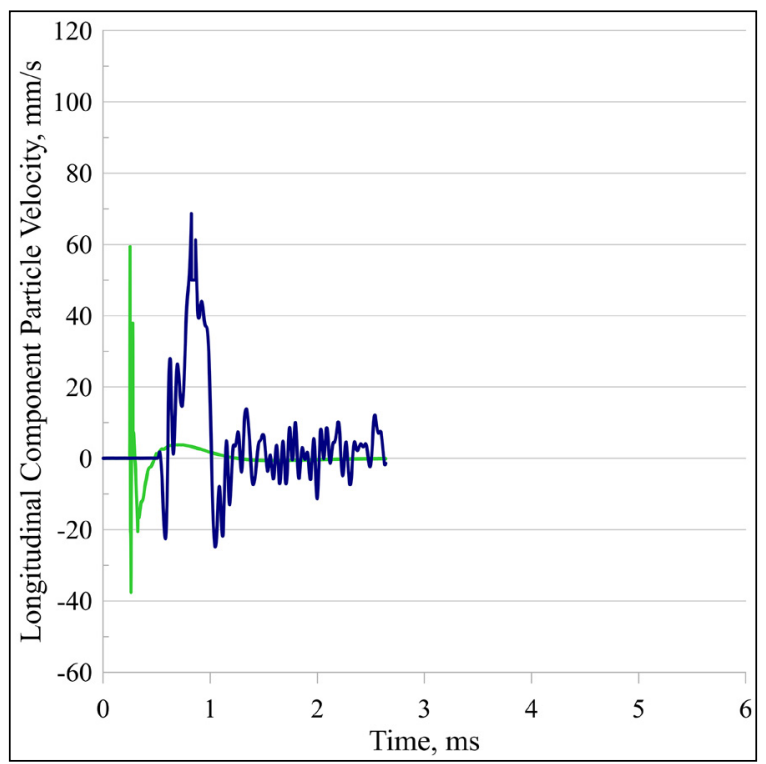

Figure 7- Comparison of actual blast longitudinal component source signal and predicted signal with numerical modeling (green true-blue numerical modeling)

\section{Results}

In certain periods, one or more of the hypothesis explaining a specific event take their place in the world as Dominant Paradigm (Yazgan, 2016). Studies contrary to such paradigms or studies that examine

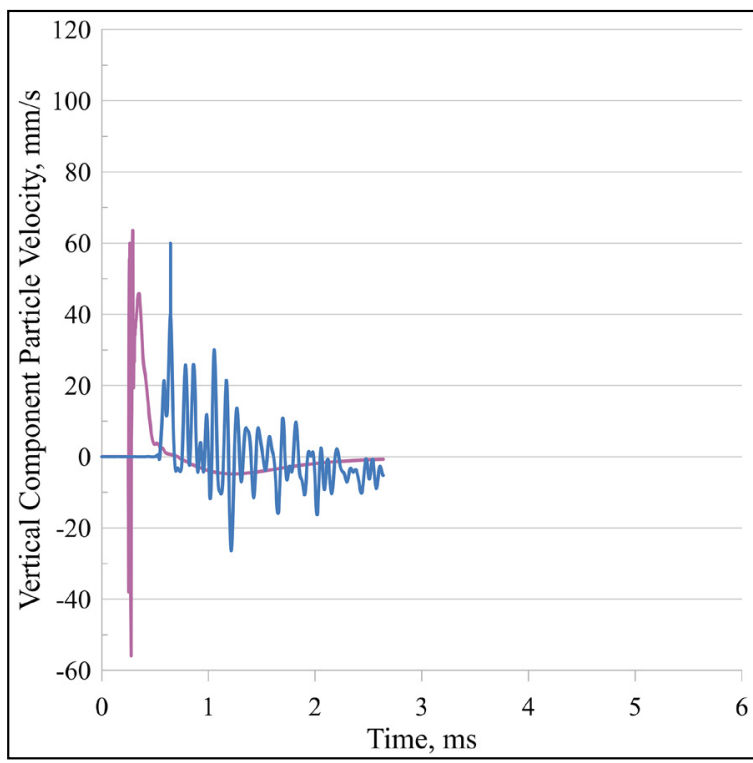

Figure 6- Comparison of the actual blast vertical component source signal and the predicted signal with numerical modeling (purple real data vs blue numerical modeling data).

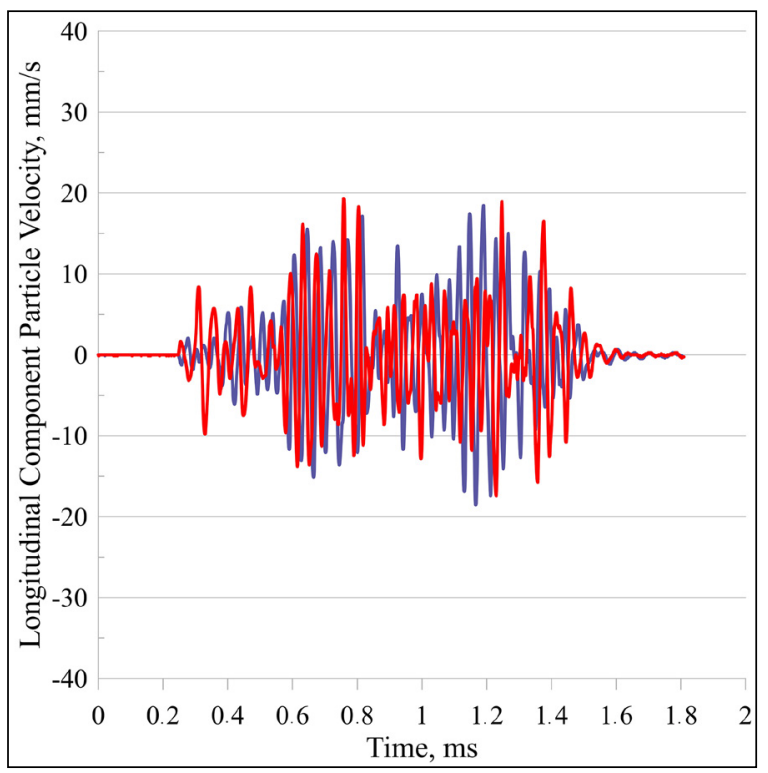

Figure 8- Numerical model predicted (red) and actual blast data (blue) (20 $\mathrm{m}$ from the blast).

the views against such paradigms do not necessarily get many compliments. Studies conforming to such paradigms often reap the benefits of their adherence that acts as a reinforcement of conformity. These benefits could range from being published in an esteemed publication to receiving financial aid. Particle velocity-scaled distance hypothesis that was first put forward in the 1960s is one of such 


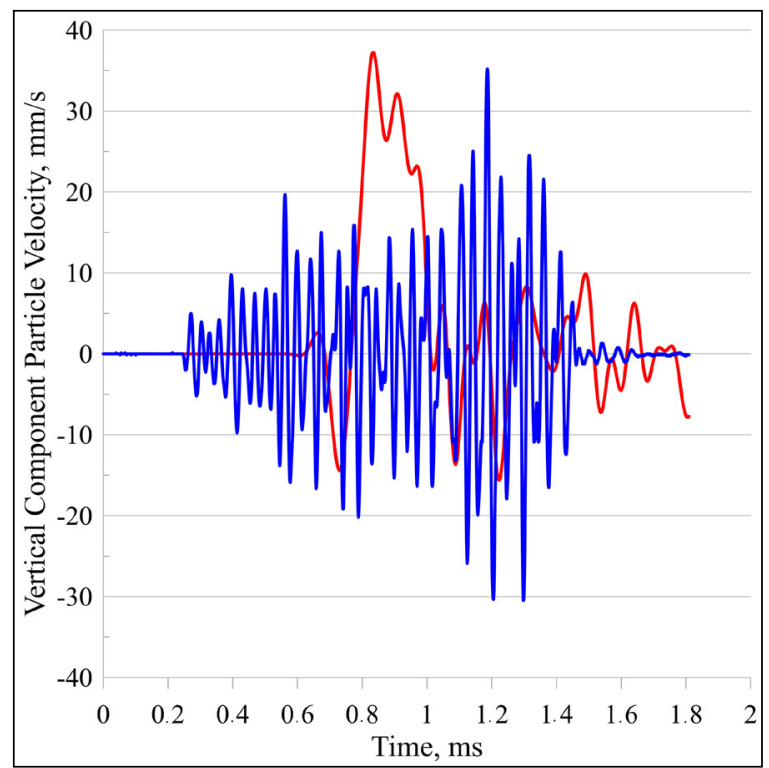

Figure 9- Numerical model predicted (red) and actual blast data (blue) (30 $\mathrm{m}$ from the blast).

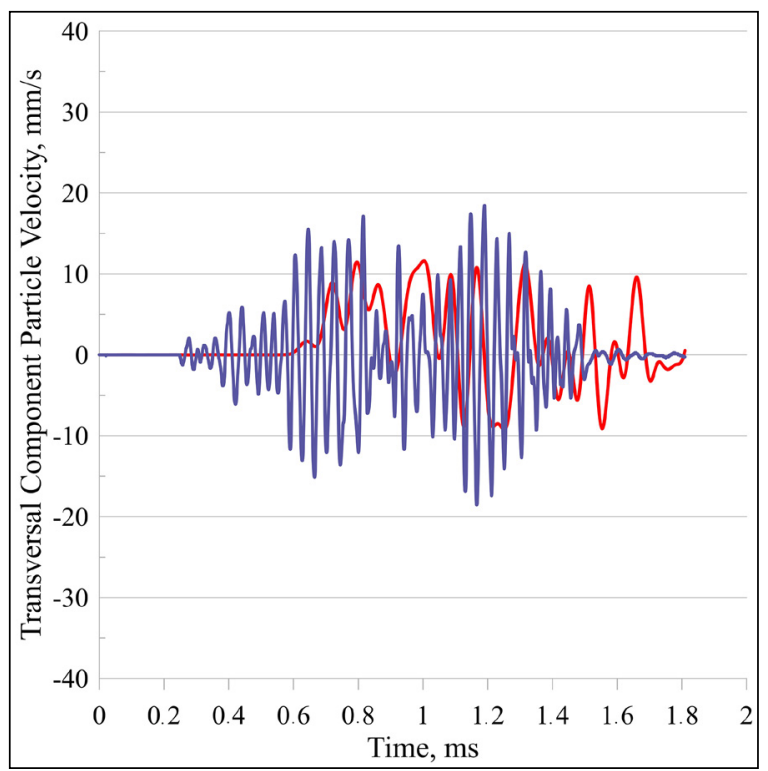

Figure 10- Numerical model predicted (red) and actual blast data (blue) (40 $\mathrm{m}$ from the blast).

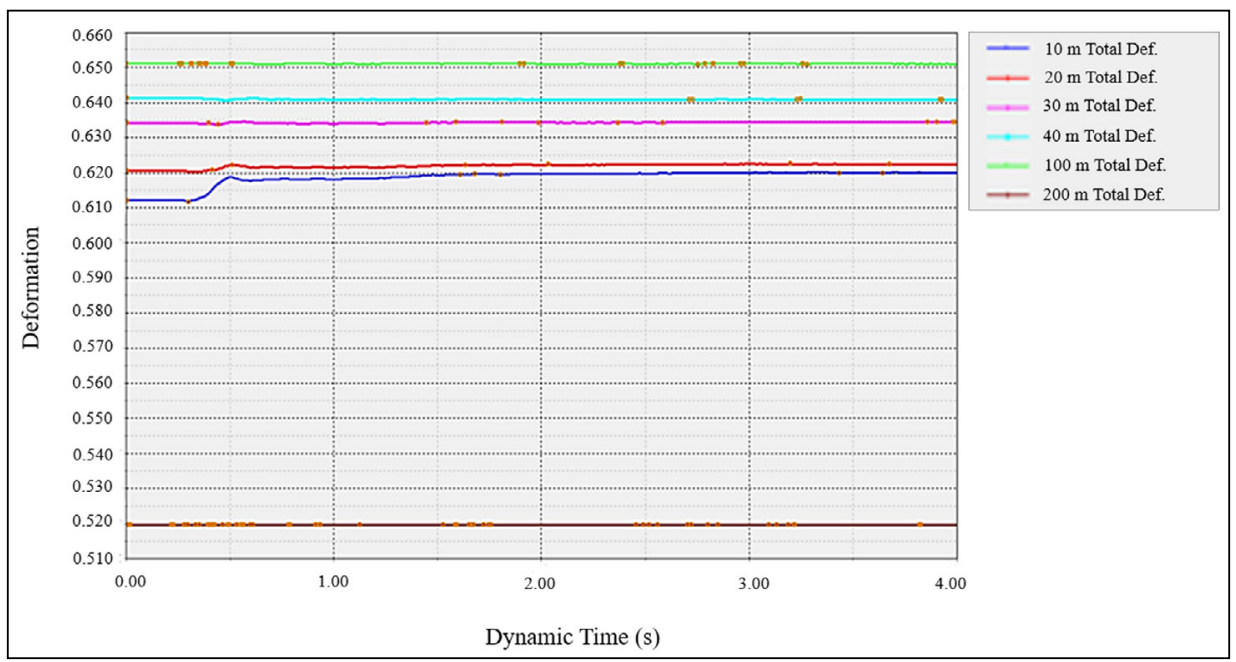

Figure 11- Total deformation amounts vary with distance in the numerical model. The $\mathrm{x}$-axis shows the dynamic time (s), the y-axis shows the amount of deformation (m).

paradigms. Although it has been 60 years, since this paradigm becoming obsolete would cause chaos by disrupting the current order, empirical formulas based on explosive restraint are still used in minimizing and estimating blast-induced vibrations.

This study is very important in terms of;

- Obtaining the seismic signature caused by the seismic wave due to the pilot blast, depending on the geotechnical parameters of the study area, such as the number of discontinuity sets, orientation, direction, groundwater and dealing with this signature,

- Obtaining the seismic energy formed in the middle of the blast, also known as the point zero, from the pilot and group blast signals.

- Feeding this signal into the 3D dynamic numerical model and estimating vibrations in the target point using defined blast parameters, 
- Determining the plastic deformation area of the blast in which the blast does not display linear behavior using both numerical and seismic quality factor calculation,

- Being able to input actual blast effects into slope stability analyses in the planning stage, through estimation of dynamic blast effects.

- Allowing blast and geotechnical engineers to produce more sensitive designs.

and aims to demolish the current paradigm.

\section{Acknowledgements}

We thank TÜMAD Lapseki Gold Mine, henceforth its executives, engineers who assisted us in the field and for the underground applications, İmbat Mining, its executives and engineers, all of whom opened their doors for us to allow the conduct of these experiments.

\section{References}

Aksoy, G. G., Aksoy, C. O. 2020. Patlatma kaynaklı titreşimlerin tahmininde sismik kalite faktörü kullanımı. MT Bilimsel, 8(18), 133-145.

Aksoy, C. O., Uyar, G. G. 2014-2017. Deformasyona izin vermeyen tahkimat sisteminin geliştirilmesi. TÜBİTAK, Proje No: 114M566.

Blair, D. P. 2020. Approximate models of blast vibration in non-isotropic rock masses. International Journal of Rock Mechanics and Mining Sciences 128, 104-245.
Singh, S. P., Narendrula, R. 2004. Assessment and prediction of rock mass damage by blast vibrations. International Proceeding 13th International Symposium Mine Planning and Equipment Selection, Wroclaw, 317-322, 1-3.

Simangunsong, G. M., Wahyudi, S. 2015. Effect of bedding plane on prediction blast-induced ground vibration in open pit coal mines. International Journal of Rock Mechanism and Mining Science $79,1-8$.

Uyar, G. G., Aksoy, C. O. 2019. Comparative review and interpretation of the conventional and new methods in blast vibration analyses. Geomechanics and Engineering 18(5), 545-554.

Uyar, G. G., Aksoy, C. O., Ecevitoğlu, B., Kaypak, B. 2014. Partition of elastic/plastic energy in mine blast. International Conference of Mining, Material and Metallurgy, MMM'14.

Uyar, G. G., Ecevitoğlu, B. 2008. Waveform analysis in mitigation of blast_induced vibrations. Journal of Applied Geophysics 66, 25-30.

Yazgan, Y. 2016. Yaşantıların Psikolojisi ve Biyolojisi. Remzi Kitabevi, 285.

Zhou, J. M. 2016. The effect of joints on rock masses under blast-1nduced vibration. $\mathrm{PhD}$ Thesis, University of Hong Kong.

Zou, F., Gong, L. 2017. Experimental study on the propagation characteristics of blasting vibration in layered rock masses. Internat,onal Asia-Pacific Engineering Technology Conference, Kuala Lumpur, 889-896, 25-26. 